\title{
Future concepts in bronchodilation for COPD: dual- versus monotherapy
}

\author{
Dave Singh ${ }^{1}$, James F. Donohue ${ }^{2}$, Isabelle H. Boucot ${ }^{3}$, Neil C. Barnes ${ }^{5,6}$, Chris Compton ${ }^{5}$ and \\ Fernando J. Martinez ${ }^{6}$
}

${ }^{1}$ Centre for Respiratory Medicine and Allergy, University of Manchester, Manchester University NHS Foundation Trust, Manchester, UK. ${ }^{2}$ Division of Pulmonary Diseases and Critical Care Medicine, University of North Carolina, School of Medicine, Chapel Hill, NC, USA. ${ }^{3}$ Medical Emerging Markets, GSK, Brentford, UK. ${ }^{4}$ William Harvey Research Institute, Barts and the London School of Medicine and Dentistry, London, UK. ${ }^{5}$ Global Specialty \& Primary Care, GSK, Brentford, UK. ${ }^{6}$ Weill Cornell Medical College, New York, NY, USA.

Corresponding author: Dave Singh (dsingh@meu.org.uk)

Shareable abstract (@ERSpublications)

Many patients with COPD experience debilitating symptoms even when using a single bronchodilator. Intensifying treatment with dual bronchodilation as early as possible may improve outcomes for patients with COPD. https://bit.ly/3myMtzp

Cite this article as: Singh D, Donohue JF, Boucot IH, et al. Future concepts in bronchodilation for COPD: dual- versus monotherapy. Eur Respir Rev 2021; 30: 210023 [DOI: 10.1183/16000617.0023-2021].

Copyright (c)The authors 2021

This version is distributed under the terms of the Creative Commons Attribution Non-Commercial Licence 4.0 . For commercial reproduction rights and permissions contact permissions@ersnet.org

This article has supplementary material available from err.ersjournals.com

Received: 28 Jan 2021 Accepted: 6 April 202

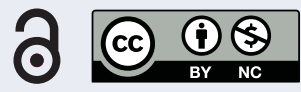

\section{Abstract}

Most patients with COPD are recommended to initiate maintenance therapy with a single long-acting bronchodilator, such as a long-acting muscarinic antagonist or long-acting $\beta_{2}$-agonist. However, many patients receiving mono-bronchodilation continue to experience high symptom burden, suggesting that patients are frequently not receiving optimal treatment. Treatment goals for COPD are often broad and not individually tailored, making initial treatment response assessments difficult. A personalised approach to initial maintenance therapy, based upon an individual's symptom burden and exacerbation risk, may be more appropriate.

An alternative approach would be to maximise bronchodilation early in the disease course of all patients with COPD. Evidence suggests that dual bronchodilation has greater and consistent efficacy for lung function and symptoms than mono-bronchodilation, whilst potentially reducing the risk of exacerbations and disease deterioration, with a similar safety profile to mono-bronchodilators. Improvements in lung function and symptoms between dual- and mono-bronchodilation have also been demonstrated in maintenance-naïve patients, who are most likely to resemble those at first presentation in a clinical setting. Despite promising results, there are several evidence gaps that need to be addressed to allow decision makers to evaluate the merits of a widespread earlier introduction of dual bronchodilation.

\section{Introduction}

COPD is a heterogenous condition estimated to affect over 380 million patients worldwide in 2010 [1], and is a leading cause of morbidity and mortality associated with substantial economic burden [2]. The chronic and complex nature of COPD means that symptom improvement alone may not be a reliable indicator of treatment success and, unlike asthma where the concept of control is well established [3], there is currently no widely accepted definition of COPD control $[4,5]$.

A personalised approach to COPD treatment has been advocated in recent years, with initial maintenance and follow-up treatment recommendations differing according to clinical characteristics [2, 6]. According to the 2021 Global Initiative for Chronic Obstructive Lung Disease (GOLD) report, dual long-acting muscarinic antagonist/long-acting $\beta_{2}$-agonist (LAMA/LABA) combination therapy may be considered as initial treatment for symptomatic patients with low exacerbation risk (GOLD B) and severe breathlessness, or for highly symptomatic (COPD Assessment Test $(\mathrm{CAT}) \geqslant 20$ ) patients with high exacerbation risk (GOLD D) [2]. The American Thoracic Society clinical practice guidelines, using the Grading of Recommendations Assessment, Development and Evaluation (GRADE) approach, provided a strong recommendation in favour of LAMA/LABA combination therapy over long-acting bronchodilator (LABD) monotherapy for patients with dyspnoea or exercise intolerance [7]. 
Although LABD monotherapy has proven efficacy in COPD [8], almost half of patients receiving this treatment continue to experience a high symptom burden [9], suggesting that monotherapy may be suboptimal for many patients. Inadequate symptom control may lead to increased rates of morbidity and mortality [10-12] and result in an increased economic burden, as highly symptomatic patients utilise more healthcare, with more frequent hospitalisations and higher in-patient costs [13]. Similarly, among maintenance-treated patients who frequently use short-acting bronchodilator rescue medication, those with severe dyspnoea utilise significantly more healthcare resources and experience more frequent exacerbations than patients with mild dyspnoea [14]. This raises the possibility of wide-ranging benefits from intensifying bronchodilation early in the disease course to reduce symptom burden. To investigate this, in this review we discuss: 1) current COPD treatment goals and their appropriateness for long-term COPD management; 2) evidence for dual- versus mono-bronchodilation as initial maintenance therapy in COPD; and 3) key evidence gaps in the optimal approach to initial bronchodilator therapy in COPD.

\section{Defining treatment goals in COPD}

There are three intrinsically linked over-arching components of COPD that need to be considered when defining treatment goals (figure 1): 1) disease activity, which describes the intensity of underlying biological mechanisms that drive disease progression and worsening of disease severity; 2) disease severity, which relates to the degree of functional impairment such as airflow limitation [10, 15]; and 3) disease impact, which is a patient's perception of the severity and activity of their disease, and any modifications to their activities of daily living. These components are intrinsically linked. Disease activity drives disease progression, which worsens disease severity; together disease activity and disease severity influence disease impact (figure 1).

Current goals for COPD pharmacological treatment aim to prevent exacerbations and improve symptoms, thereby minimising disease activity, preventing disease progression, and ultimately reducing disease impact [2]. However, the framework for monitoring disease progression is not well defined, with no objective thresholds routinely used in clinical practice to longitudinally evaluate changes in disease burden, the quantification of disease activity and progression remains challenging. Individualised COPD treatment goals that reflect disease activity would allow physicians to monitor treatment responses and identify when treatment adjustments are necessary. Asthma guidelines recommend assessing treatment responses 3-6 months after treatment initiation [3] but in COPD, evidence suggests that LABD treatment effects can be apparent within a few days of treatment initiation and that treatment responses at 4 weeks provide an early indication of longer-term responses [16]. If treatment goals with thresholds for improvement/decline over an appropriate time frame could be established for COPD, they could be used to objectively assess initial treatment benefits and inform treatment decisions earlier in the disease course.

Forced expiratory volume in $1 \mathrm{~s}\left(\mathrm{FEV}_{1}\right)$ is a marker of COPD severity and has prognostic value. However, it does not reflect the multifaceted nature of COPD or its impact on patients [17]. Although correlations between $\mathrm{FEV}_{1}$ and health status improvements have been noted in clinical trials $[18,19]$, correlations with other patient-reported outcomes (PROs) have been weak or only observed in a minority of patients [17, 20]. As most patients with COPD continue to experience symptoms despite maintenance therapy [21], it is unreasonable to define treatment goals as an absence of symptoms. Instead, a range of lung function and symptom measures should be considered when evaluating treatment effectiveness. Several PROs assess symptoms and health status in patients with COPD including the Transition Dyspnoea Index (TDI) [22], CAT [23], Evaluating Respiratory Symptoms-COPD (E-RS) [24] and St George's Respiratory Questionnaire (SGRQ) [25]. In addition, more frequent use of rescue medication is associated with worse

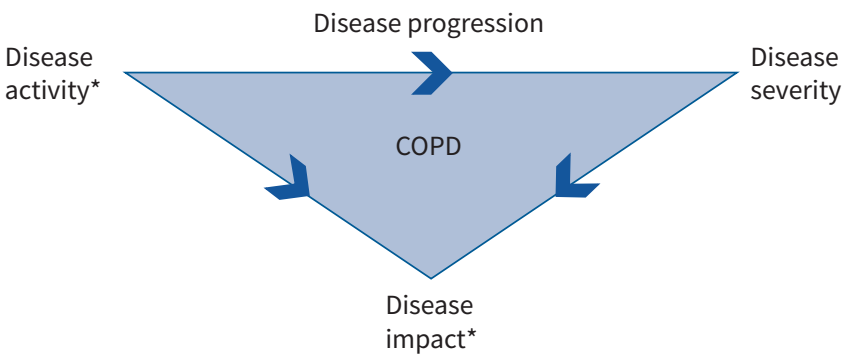

FIGURE 1 Relationship between COPD severity, activity and impact.

*: targets for pharmacological treatment. 
dyspnoea and a higher overall disease burden [14, 26], and may be another useful measure to monitor and set treatment goals in clinical settings. Composite tools with objective thresholds for multiple outcomes may provide more detailed insights into disease course and treatment response than one-dimensional measures such as $\mathrm{FEV}_{1}$ or dyspnoea severity alone [27].

\section{Relationship between symptoms and disease progression}

A history of frequent COPD exacerbations increases the risk of future disease progression [28, 29], whereas the association between a high symptom burden and future outcomes including hospitalisations and mortality is less well established [10, 30,31]. In one study, patients with a high symptom burden and low exacerbation risk (GOLD B) were approximately three times more likely to have 1-year respiratory mortality compared with patients with a low symptom burden and low exacerbation risk (GOLD A) [31]. A Danish prospective cohort analysis found that compared with individuals without COPD, patients with undiagnosed, symptomatic COPD had an increased risk of future exacerbations, pneumonia and mortality [11]. Other studies found that dyspnoea predicts mortality better than exacerbation history or lung function [32, 33], and that night-time dyspnoea is associated with increased exacerbation risk, hospital admissions and mortality [12]. Chronic cough and sputum production have also been linked with increased exacerbation risk and hospitalisations in patients with COPD [34]. However, not all studies have identified associations between symptoms and future disease progression [35]. For example, in the ASSESS study, early morning and daytime symptoms were significantly associated with the occurrence of exacerbations in the subsequent 6 months, but this association was lost when confounding variables, including exacerbation history and lung function, were accounted for [36]. Also, associations between symptom burden and future disease deterioration may partly be a consequence of the high prevalence of comorbidities that can cause dyspnoea among patients with COPD, such as cardiovascular disease [31, 32].

\section{Disease stability as a treatment goal}

Although the need to monitor COPD disease control and stability has been recognised since 2009 [37], there currently remains no accepted definition of disease control in COPD [4, 5]. SolER-CATALuÑa et al. [38] propose defining COPD control as the long-term maintenance of disease stability (ongoing period of no significant changes in disease activity, including an absence of clinical worsening and exacerbations during the observation period) and low clinical impact on the patient (adjusted to the level of severity of the disease). A prospective observational study reported that patients who achieved control had fewer symptoms, better health status, and a reduced risk of future disease complications (including exacerbations and hospitalisations) over 1-year follow-up than uncontrolled patients [5]. A post hoc analysis of the SPARK trial where only $20 \%$ of patients were classified as “controlled” using disease impact and stability as indicators of control status, found that these patients experienced significantly lower exacerbation rates during 52 weeks' follow-up than noncontrolled patients [39]. While both these studies defined disease stability as the absence of exacerbations over 3 months $[5,39]$, the analysis of SPARK also included the absence of clinical worsening assessed by CAT [39]. While there are merits to the concept of defining disease control in this way, many patients have a burden of symptoms that cannot be reduced below such thresholds.

In recent years, the clinically important deterioration (CID) concept has been introduced as a method of evaluating short-term disease worsening to provide additional insights into disease activity [40]. CID is a composite end-point that assesses early COPD disease deteriorations across $\mathrm{FEV}_{1}$, PROs and moderate/ severe exacerbations [41-44]. Several post hoc analyses, and prospective analyses of the EMAX and FULFIL trials, have used CID to assess clinically relevant worsening [41-43, 45-48]. Importantly, prognostic analyses have demonstrated that the absence of a short-term CID is linked to sustained long-term improvements in lung function and symptoms with existing maintenance therapy, whereas CID events are associated with increased risks of hospitalisation and mortality (figure 2) [46, 48-52]. Similarly, in a post hoc analysis of the FLAME study, patients who experienced a CID within 12 weeks of treatment initiation had significantly higher exacerbation rates over 52 weeks versus those without a CID [43]. In TORCH, ECLIPSE, FULFIL and IMPACT, patients without a CID also had improvements in lung function, health status and symptoms compared with patients with a CID [46, 48, 52]. These findings support the use of CID to evaluate disease stability and worsening and suggest that efforts to reduce these events early in the disease course may have long-term benefits. However, there are challenges in implementing monitoring of CID in routine clinical practice, such as the lack of routine use of PROs in many clinics. In this regard, the recent analysis of the IMPACT study shows that the CAT, which is relatively quick to administer, is the most suitable PRO for this purpose [52]. 

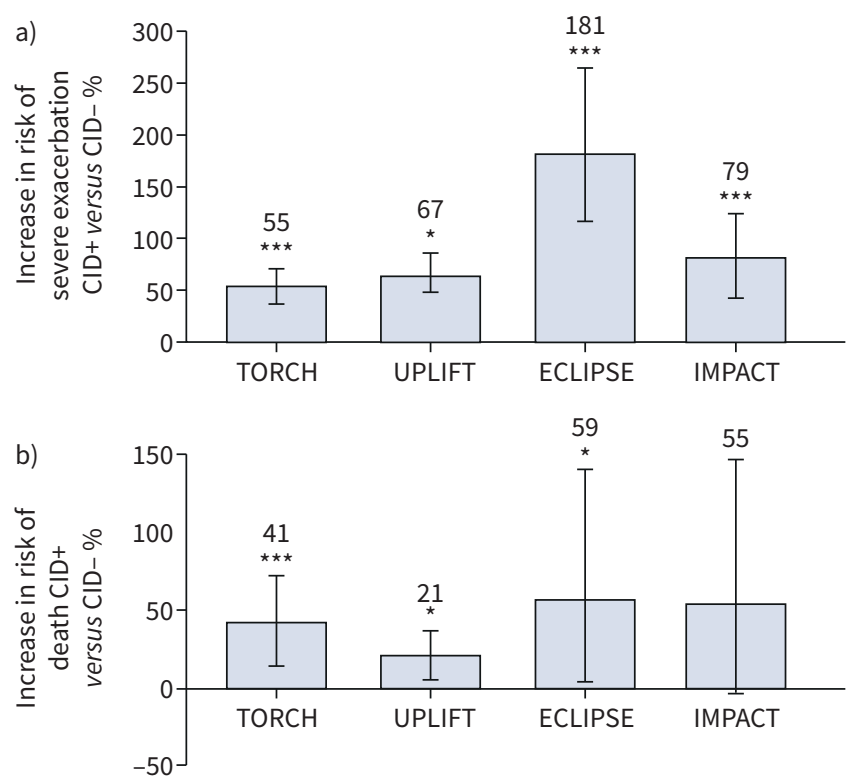

FIGURE 2 Risk of a) severe (hospitalised) exacerbations and b) mortality by clinically important deterioration (CID) status $[46,51,52]$. CID was defined as $\geqslant 100 \mathrm{~mL}$ decrease in forced expiratory volume in $1 \mathrm{~s}$, $\geqslant 4$-unit increase in St George's Respiratory Questionnaire score from baseline, and/or a moderate/severe exacerbation. CID+: patients with a CID at 6 months in the TORCH and UPLIFT studies, at 12 months in the ECLIPSE study, or at week 28 in the IMPACT study; CID-: patients without a CID in the same time frame. ${ }^{*}: p<0.05 ;{ }^{* \star}$ : $p<0.001$.

\section{Evidence for dual bronchodilation versus monotherapy}

Numerous studies have investigated the efficacy of dual-versus mono-bronchodilation in patients with COPD, many of which have focussed on symptomatic patients without enrichment for patients with a history of exacerbations, and have frequently included patients already receiving maintenance treatment [42, 47, 53-58]. Some post hoc and prospective analyses of dual-versus mono-bronchodilation have also been conducted in maintenance-naïve patients (table 1) [45, 58-65] and provide evidence concerning initial pharmacological treatment. Here, we summarise current evidence for dual- versus mono-bronchodilation in maintenance-treated and maintenance-naïve patients.

\section{Lung function}

Several meta-analyses have demonstrated greater lung function improvements with LAMA/LABA combinations versus LAMA or LABA therapies (including combinations with inhaled corticosteroids (ICS)/LABA), regardless of exacerbation history [67-69], as have numerous randomised controlled trials (RCTs), which have demonstrated early and sustained benefits [47, 53-55]. In the 24-week EMAX trial in symptomatic patients at low exacerbation risk, significant improvements in trough $\mathrm{FEV}_{1}$ were observed after 4 weeks of treatment with umeclidinium (UMEC)/vilanterol (VI) versus UMEC or salmeterol (SAL) [47]. Similarly, trough $\mathrm{FEV}_{1}$ improvements were also observed with indacaterol (IND)/glycopyrronium (GLY) versus GLY and tiotropium (TIO) monotherapy by week 4 in the SPARK study [53]. Other studies have found lung function benefits with LAMA/LABA versus monotherapy within 1 week of treatment $[54,55]$.

Lung function efficacy of dual- and mono-bronchodilation has been evaluated in maintenance-naïve patients with COPD (table 1) [45, 58-66]. In a 12-week prospective study in maintenance-naïve Japanese patients, mean $\mathrm{FEV}_{1}$ improvement with TIO/olodaterol (OLO) was two-fold higher compared with TIO [65]. A pre-specified analysis of EMAX in maintenance-naïve patients reported greater improvements in lung function with UMEC/VI versus UMEC and SAL [62]. Post hoc analyses of maintenance-naïve patients have also reported greater improvements in trough $\mathrm{FEV}_{1}$ at 24 weeks with UMEC/VI [45] and IND/GLY [61] versus TIO and more recently in a pooled analysis of PINNACLE studies with GLY/formoterol fumarate (FOR) versus the respective monotherapies [59]. Greater improvements in $\mathrm{FEV}_{1}$ area under the curve from $0-3 \mathrm{~h}\left(\mathrm{AUC}_{0-3}\right)$ with TIO/OLO versus TIO alone have also been demonstrated [58]. Furthermore, post hoc analyses of maintenance-naïve patients in the OTEMTO and TONADO trials by GOLD stage, Baseline Dyspnoea Index (BDI) score or baseline SGRQ total score showed that there were significantly greater improvements in trough $\mathrm{FEV}_{1}$ at 12 weeks with TIO/OLO versus TIO in patients with 
TABLE 1 Summary of studies comparing the efficacy of long-acting muscarinic antagonist/long-acting $\beta_{2}$-agonist with monotherapy in maintenance-naïve patients with COPD

First author [Ref.]

Study

Lung function

Symptoms/disease impact

Risk of a CID event or exacerbation

ZHENG [59] POst hoc analysis of two phase III PINNACLE studies: GLY/FOR, GLY,

FOR or placebo for 24 weeks

MN patients had no LABD in the 30 days prior to screening

NAYA [60] $\begin{gathered}\text { Post hoc analysis of two replicate } \\ \text { RCTs: UMEC/VI, UMEC, VI and } \\ \text { placebo for } 24 \text { weeks in } \\ \text { exacerbation-free patients }\end{gathered}$
MURO [61]
PRISE, hHINE and SPARK trials:
IND/GLY versus TIO and GLY over
24 weeks in MN patients

$\mathrm{FEV}_{1}$ mean change from baseline treatment difference: GLY/FOR versus GLY $73 \mathrm{~mL}$; versus FOR $56 \mathrm{~mL}$; versus placebo $152 \mathrm{~mL}$; all $\mathrm{p}<0.0001$ baseline treatment difference puffs/day (95\%

Trough $\mathrm{FEV}_{1} \mathrm{LS}$ mean $(95 \% \mathrm{Cl})$ change from baseline treatment difference: UMEC/ VI versus: UMEC $60(14-106) \mathrm{mL}, \mathrm{p}=0.011$; versus VI $72(27-117) \mathrm{mL}, \mathrm{p}=0.010$; versus placebo $209(159-260) \mathrm{mL}, \mathrm{p}<0.001$

Trough $\mathrm{FEV}_{1}$ mean $(95 \% \mathrm{Cl})$ change from baseline treatment difference: IND/GLY versus TIO 86 (54-118) $\mathrm{mL}$; versus GLY 80 $(47-112) \mathrm{mL}$

$\mathrm{FEV}_{1}$ mean $(95 \% \mathrm{Cl})$ change from baseline treatment difference: TIO/OLO versus TIO 139 (53-225) $\mathrm{mL} ; \mathrm{p}=0.002$

IC mean $(95 \% \mathrm{Cl})$ change from baseline treatment difference: TIO/OLO versus TIO

$$
115(-40-267) \mathrm{mL} ; \mathrm{p}=0.13
$$

FVC mean $(95 \% \mathrm{CI})$ change from baseline treatment difference: TIO/OLO versus TIO $-0.809(-2.829-1.210)$

Physical activity change in duration $(95 \% \mathrm{Cl})$
SGRQ mean change from baseline treatment difference $(95 \% \mathrm{Cl})$ : GLY/FOR versus GLY -0.39 (-1.92-1.14), $\mathrm{p}=0.6179$; versus FOR $0.81(-0.69-2.31), \mathrm{p}=0.2903$; versus placebo $-1.75(-3.71-0.22), p=0.0810)$ Rescue medication mean change from $\mathrm{Cl})$ : GLY/FOR versus GLY $-0.2(-0.6-0.2)$, $\mathrm{p}=0.2740$; versus $-0.2(-0.5-0.2), \mathrm{p}=0.3845$ versus placebo $-0.9(-1.4--0.5), p<0.0001$

CID \% risk reduction: GLY/FOR versus GLY $21 \%, p=0.0018$; versus FOR $17 \%$, $p=0.0157$; versus placebo $43 \%, p<0.0001$

Moderate/severe exacerbation \% risk reduction $(95 \% \mathrm{Cl})$ : UMEC/VI versus: UMEC $51(-8-77) \%, \mathrm{p}=0.076$; versus $\mathrm{V}$ $60(16-81) \%, p=0.016$; versus placebo $62(15-83) \%, p=0.018$

TDI focal score mean $(95 \% \mathrm{CI})$ change from baseline treatment difference: IND/GLY versus TIO $0.634(-0.012-1.281)$; versus $\mathrm{GLY}$ $0.286(-0.345-0.918)$

SGRQ total score mean $(95 \% \mathrm{Cl})$ change from baseline treatment difference: IND/GLY versus TIO -1.808 (-3.783-0.168); versus GLY

Rescue medication use mean $(95 \% \mathrm{Cl})$

change from baseline puffs/day treatment difference: IND/GLY $-0.531(-0.869--0.192)$; versus GLY $-0.499(-0.849--0.150)$

TDI focal score mean $(95 \% \mathrm{CI})$ change from

baseline treatment difference: TIO/OLO versus TIO 0.9 (0.2-1.8); $p=0.02$ at $\geqslant 2.0$ METs from baseline treatment difference: TIO/OLO versus TIO 2.5 (-19.024.0) $\min ; \mathrm{p}=0.82$

202) $\mathrm{mL} ; \mathrm{p}=0.46$ 
TABLE 1 Continued

First author [Ref.]

Study

Lung function

Symptoms/disease impact

Risk of a CID event or exacerbation

BJERMER (unpublished Pre-specified prospective analysis data) PMAX: UMEC/VI versus UMEC and SAL over 24 weeks MN and MT patients

\footnotetext{
SINGH [63] Post hoc analysis of ACL/FOR and AUGMENT RCTs: ACL/FOR versus

$A C L, F O R$ and placebo over

24 weeks

MN patients
}

Trough FEV 1 LS mean $(95 \% \mathrm{Cl})$ change from baseline treatment difference: UMEC/

$\mathrm{VI}$ versus UMEC $44(1-87) \mathrm{mL}, \mathrm{p}=0.045$; versus SAL $128(85-171) \mathrm{mL}, \mathrm{p}<0.001$ Trough FVC LS mean $(95 \% \mathrm{Cl})$ change from baseline treatment difference: UMEC $\mathrm{VI}$ versus UMEC $82(15-148) \mathrm{mL}, \mathrm{p}=0.016$; versus SAL $177(110-243) \mathrm{mL}, \mathrm{p}<0.001$ Trough IC LS mean $(95 \% \mathrm{Cl})$ change from baseline treatment difference: UMEC/VI versus UMEC 29 (-37-94) $\mathrm{mL}, \mathrm{p}=0.388$; versus SAL $71(6-136) \mathrm{mL}, \mathrm{p}=0.032$

Trough $\mathrm{FEV}_{1}$ mean change from baseline treatment difference: $\mathrm{ACL} / \mathrm{FOR}$ versus $\mathrm{ACL}$

$14 \mathrm{~mL}$, Ns; versus FOR $57 \mathrm{~mL}, \mathrm{p}<0.01$; versus placebo $134 \mathrm{~mL}, \mathrm{p}<0.001$
TDI focal score LS mean $(95 \% \mathrm{CI})$ change from baseline treatment difference: UMEC/VI versus UMEC $-0.37(-0.21-0.96), \mathrm{p}=0.210$; versus SAL $0.47(-0.10-1.05), p=0.108$ E-RS total score $\mathrm{LS}$ mean $(95 \% \mathrm{Cl})$ change from baseline treatment difference: UMEC/VI versus UMEC $-0.26(-1.04-0.53), p=0.524$; versus SAL $-0.58(-1.36-0.20), p=0.148$ SGRQ total score LS mean $(95 \% \mathrm{Cl})$ change from baseline treatment difference: UMEC/VI versus UMEC $0.30(-2.00-2.60), p=0.797$; versus SAL $-1.12(-3.40-1.17), p=0.338$ CAT total score LS mean $(95 \% \mathrm{Cl})$ change from baseline treatment difference UMEC/VI versus UMEC $-0.3(-1.4-0.8), p=0.599$; versus

$$
\text { SAL }-1.0(-2.1-0.1), p=0.067
$$

Rescue medication use LS mean $(95 \% \mathrm{CI})$

change from baseline puffs/day treatmen difference UMEC/VI versus UMEC -0.44

$(-0.73-0.16), \mathrm{p}=0.002$; versus $\mathrm{SAL}-0.37$ $(-0.66--0.09), p=0.010$

Rescue medication use LS mean $(95 \% \mathrm{Cl}) \%$ rescue medication-free days treatment difference UMEC/VI versus UMEC 10.6

(4.9-16.3), $p<0.001$; versus SAL 8.3

$$
(2.6-14.0), p=0.005
$$

TDI focal score mean $(95 \% \mathrm{Cl})$ change from baseline treatment difference: ACL/FOR

versus $A C L$ 1.166, $p<0.001$; versus FOR 0.0916 , $p<0.01$; versus placebo $1.535, p<0.001$

E-RS total score mean $(95 \% \mathrm{CI})$ change from baseline treatment difference: $\mathrm{ACL} / \mathrm{FOR}$ versus $\mathrm{ACL}-0.818, \mathrm{p}<0.05$; versus $\mathrm{FOR}$ $-0.827, p<0.05$; versus placebo $-1.445, p<0.001$

SGRQ total score mean $(95 \% \mathrm{CI})$ change from baseline treatment difference: $A C L / F O R$ versus $\mathrm{ACL}-3.1, \mathrm{p}<0.01$; versus $\mathrm{FOR}-2.3$, $p<0.05$; versus placebo $-5.3, p<0.001$
$\mathrm{CID}$ (exacerbation, $\mathrm{FEV}_{1}$, SGRQ) HR (95\% Cl): UMEC/VI versus UMEC 1.16 (0.88-1.52), $\mathrm{p}=0.292$; versus SAL 0.78 $(0.60-1.00), p=0.048$

CID (exacerbation, $\left.\mathrm{FEV}_{1}, \mathrm{CAT}\right) \mathrm{HR}(95 \%$ $\mathrm{CI})$ : UMEC/VI versus UMEC $0.90(0.69-$ 1.18), $\mathrm{p}=0.454$; versus SAL 0.70 (0.540.90), $p=0.006$

CID (exacerbation, SGRQ, CAT, TDI) HR (95\% CI): UMEC/VI versus UMEC 0.84 (0.67-1.06), $\mathrm{p}=0.144$; versus SAL 0.80 $(0.64-1.00), p=0.052$ 
Pooled analysis of three 24-week studies; UMEC/VI versus TIO in MN patients

Trough $\mathrm{FEV}_{1} \mathrm{LS}$ mean $(95 \% \mathrm{CI})$ change from baseline treatment difference: UMEC/ $\mathrm{VI}$ versus TIO $146(102-189) \mathrm{mL}, \mathrm{p}<0.001$

$\mathrm{FEV}_{1} \mathrm{AUC}_{0-3}:$ TIO/OLO versus TIO significant improvements

SINGH [58] Post hoc analysis of OTEMTO 1 and OTEMTO 2 RCTs: TIO/OLO versus $\mathrm{TIO}$ and placebo over 12 weeks

$\mathrm{MN}$ and MT subgroups

FERGUSON [64] Post hoc analysis of the two TORNADO trials: TIO/OLO versus

TIO and OLO at 24 weeks

Subgroup analysis by prior

bronchodilator treatment

BuHL [66] Post hoc analysis of four pooled studies TIO/OLO versus $\mathrm{TIO}$ at

12 weeks in MN patients

Subgroup analysis by GOLD stage, BDI score or baseline SGRO total score
Trough $\mathrm{FEV}_{1}$ : TIO/OLO versus TIO NS

Trough $\mathrm{FEV}_{1}$ adjusted mean $\pm \mathrm{SE}$ change from baseline

GOLD 2: TIO/OLO $(5 / 5 \mu \mathrm{g}) 146 \pm 14 \mathrm{~mL}$ difference

GOLD 3/4: TIO/OLO (5/5 $\mu \mathrm{g}) 148+14 \mathrm{~mL}$

versus TIO $(5 \mu \mathrm{g}) 79 \pm 13 \mathrm{~mL}$, significant difference

Trough $\mathrm{FEV}_{1}$ adjusted mean $(95 \% \mathrm{Cl})$ change from baseline treatment difference (TIO/OLO versus TIO):

GOLD 2: $56(25-87) \mathrm{mL}, \mathrm{p}=0.0004$

GOLD 3: 51 (11-91) mL, $p=0.0122$

$\mathrm{BDI} \leqslant 6: 62(29-95) \mathrm{mL}, \mathrm{p}=0.0002$

$\mathrm{BDI}>6$ : $54(21-86) \mathrm{mL}, \mathrm{p}=0.0012$

SGRQ <median: 41 (8-74) $\mathrm{mL}, \mathrm{p}=0.0138$

SGRQ $\geqslant$ median: $68(35-101) \mathrm{mL}, \mathrm{p}<0.0001$ versus TIO $(5 \mu \mathrm{g}) 68 \pm 14 \mathrm{~mL}$, significant
SGRQ total score mean $(95 \% \mathrm{CI})$ change from baseline treatment difference: UMEC/VI

Risk of a first CID HR (95\% CI): UMEC/ versus $\mathrm{TIO}$ NS

Rescue medication mean $(95 \% \mathrm{Cl})$ change

from baseline puffs/day treatment

difference: UMEC/VI versus TIO $-0.5(-0.9$ $0.0), p=0.066$

TDI focal score: TIO/OLO versus TIO significant improvements

SGRO total score: TIO/OLO versus TIO significant improvements
SGRQ total score adjusted mean $(95 \% \mathrm{Cl})$

change from baseline treatment difference (TIO/OLO versus TIO):

GOLD 2: $-2.02(-3.69--0.36), p=0.0171$

GOLD 3: $-1.36(-3.85-1.13), p=0.2841$

$\mathrm{BDI} \leqslant 6:-2.41(-4.40--0.41), p=0.0183$

$\mathrm{BDI}>6$ : $-1.70(-3.49-0.08), \mathrm{p}=0.0617$

SGRQ <median: $-1.56(-3.14-0.04), p=0.0562$

SGRQ $\geqslant$ median: $-1.97(-4.17-0.23)$, $\mathrm{p}=0.0786$

TDI focal score adjusted mean $(95 \% \mathrm{CI})$

change from baseline treatment difference

(TIO/OLO versus TIO):

GOLD 2: $0.52(0.10-0.94), p=0.0152$

GOLD 3: $0.18(-0.43-0.80), p=0.5628$

$\mathrm{BDI} \leqslant 6: 0.37(-0.09-0.83), \mathrm{p}=0.1152$

BDI >6: $0.50(0.02-0.98), p=0.0415$

SGRQ <median: 0.31

$(-0.14-0.77), p=0.1732$

SGRQ $\geqslant$ median: $0.54(0.05-1.03), p=0.0295$

CID: clinically important deterioration; GLY: glycopyrrolate; FOR: formoterol fumarate; MN: maintenance-naïve; LABD: long-acting bronchodilator; FEV : forced expiratory volume in $1 \mathrm{~s}$; SGRO: St George's Respiratory Questionnaire; RCT: randomised controlled trial; UMEC: umeclidinium; VI: vilanterol; LS: least Squares; IND: indacaterol; TIO: tiotropium; TDI: Transition Dyspnoea Index; OLO: olodaterol; IC: inspiratory capacity; FVC: forced vital capacity; METs: metabolic equivalents; SAL: salmeterol; MT: maintenance-treated; E-RS: Evaluating Respiratory Symptoms-COPD; CAT: COPD Assessment Test; ACL: aclidinium; Ns: not significant; $A_{U-3}$ : area under the curve from 0-3 h; GOLD: Global Initiative for Chronic Obstructive Lung Disease; BDI: Baseline Dyspnoea Index. "\#: data for maintenance-treated subgroups are presented in supplementary table 1. 
GOLD 2 and GOLD 3 COPD, and regardless of their BDI or SGRQ scores at baseline [66], suggesting that dual therapy is beneficial for maintenance-naïve patients, irrespective of disease severity.

\section{Symptom and health status outcomes}

Several RCTs and large meta-analyses have demonstrated greater efficacy with LAMA/LABA combinations versus monotherapy across multiple symptoms and health status measures [47, 53, 54, 56, 67-74]. For example, EMAX demonstrated early and sustained improvements in TDI focal score and E-RS total score from week 4 , and a greater proportion of CAT responders ( $\geqslant 2$ unit increase from baseline), with UMEC/VI versus UMEC and SAL [47]. In SPARK, IND/GLY demonstrated significant improvements in SGRQ score versus monotherapy in patients with high exacerbation risk [53]. Dual bronchodilation has also been found to be more effective at reducing rescue medication use (puffs/day) compared with mono-bronchodilation [47, 53, 67, 75, 76]. Evidence also suggests exercise capacity such as activity-related breathlessness and inspiratory capacity are improved by dual therapy compared with monotherapy [74, 77-80]. However, not all studies have identified consistent improvements in symptom or health status outcomes with LAMA/LABA versus monotherapy [45, 47, 81-84], although some of these studies were not powered to detect symptom burden treatment differences $[47,81]$, which may partially explain these inconsistencies.

Several analyses have also compared dual- and mono-bronchodilation efficacy for symptom and health status outcomes in maintenance-naïve patients (table 1). In a pooled post hoc analysis, IND/GLY showed significant improvements in SGRQ total score and TDI focal score versus TIO in bronchodilator-naïve patients (although ICS use was permitted) [61]. However, in a post hoc analysis of three 24-week trials, SGRQ total score improvements with IND/GLY versus TIO were not significant in the maintenance-naïve subgroup [45]. In a post hoc analysis of maintenance-naïve patients, TIO/OLO significantly improved mean SGRQ total score and TDI focal score versus TIO [58]. A pooled post hoc analysis of maintenance-naïve patients found an overall benefit for TIO/OLO versus TIO on SGRQ and TDI outcomes, with no convincing evidence of a greater magnitude of effect in any subgroup analysed (GOLD 2, GOLD 3, BDI $\leqslant 6$, BDI >6, SGRQ <median, SGRQ $\geqslant$ median) [66]. Another post hoc analysis reported significant improvements over 24 weeks in SGRQ, TDI and E-RS total scores with aclidinium (ACL)/FOR versus ACL and FOR in maintenance-naïve patients [63]. Significant reductions in rescue medication use with dual- versus mono-bronchodilation have also been identified in several studies [45, 59, 61]. There is little evidence of the impact of dual therapy on physical activity in maintenance-naïve patients. The SCOPE study in Japanese patients found no significant difference in 6-min walk distance, daily number of steps or changes in the duration of physical activity in patients treated with TIO/OLO versus TIO [65].

In summary, most studies investigating LAMA/LABA versus monotherapy were not powered for maintenance-naïve patients; the smaller sample sizes for these subgroup comparisons may contribute to the lack of statistical significance observed in some studies.

\section{Exacerbations}

Dual bronchodilation is recommended as an initial maintenance therapy option for highly symptomatic patients with a history of exacerbations (GOLD D) [2]. In SPARK, patients with a high risk of exacerbations had a significantly reduced risk of future moderate/severe exacerbations with IND/GLY versus GLY (12\% risk reduction) but not TIO (10\%, nonsignificant risk reduction) [53]. The DYNAGITO trial found a $7 \%$ reduction in the risk of future exacerbations with TIO/OLO versus TIO in patients with a history of exacerbations, but this was below the trial's pre-defined threshold for statistical significance [85]. Consistent with this, in patients with both low and high exacerbation risk, a network meta-analysis of over 16 trials found that LAMA/LABA dual therapy significantly reduced the risk of moderate/severe exacerbations versus LABA (18\% reduction) but not LAMA [68]; similar findings were reported in a pooled analysis of 23 studies [18]. These data suggest that LAMAs have superior efficacy for preventing exacerbations than LABAs, and that although LAMA/LABA combination treatment may not provide significant benefits over LAMA monotherapy in this regard, there is a trend towards a benefit. However, it is important to consider patient withdrawal in COPD clinical trials as it may reduce exacerbation outcome treatment differences because of a healthy survivor effect [86]. In EMAX, the risk of a first exacerbation was numerically lower (19\%) for UMEC/VI compared with UMEC, and significantly lower (36\%) for UMEC/VI compared with SAL [47] but the composite end-point of reduced risk of exacerbation and study treatment withdrawal was significantly reduced with UMEC/VI compared with both monotherapies, suggesting that this combined composite may better capture overall treatment benefits [87].

To investigate whether prior maintenance therapy impacts reductions in exacerbation risk provided by bronchodilation, NAYA et al. [60] conducted a post hoc analysis of two 24-week RCTs to compare the time 
to first exacerbation with UMEC/VI versus UMEC and VI in maintenance-naïve and maintenance-treated subgroups. In maintenance-naïve patients, UMEC/VI significantly reduced the risk of a moderate-to-severe exacerbation versus VI, but not UMEC, whereas no significant reductions in exacerbation risk were observed with UMEC/VI versus monotherapy in maintenance-treated patients [60]. These data suggest that maintenance-naïve patients who participate in clinical trials benefit more from dual bronchodilation than those with prior maintenance therapy, and the confounding effect of continuing ICS treatment is important in this regard.

\section{Clinically important deteriorations}

In a post hoc analysis of two 24-week RCTs in symptomatic patients with a low exacerbation risk, UMEC/VI significantly reduced the risk of a first CID event (defined as $\geqslant 100 \mathrm{~mL}$ decrease in trough $\mathrm{FEV}_{1}, \geqslant 4$-unit increase in SGRQ total score, or a moderate/severe exacerbation) versus TIO, UMEC and VI monotherapy [41]. Similar findings for UMEC/VI versus TIO were observed in a post hoc analysis of three 24-week RCTs [45] and a post hoc analysis of three 26-week studies reported a significantly reduced risk of a first CID event (with the same definition, or as described but with $\geqslant 1$-unit decrease in TDI score replacing trough $\mathrm{FEV}_{1}$ ) with IND/GLY versus TIO [42]. In the first prospective CID analysis of treatment differences between dual- and mono-bronchodilation according to three CID definitions, the EMAX trial found that patients receiving UMEC/VI had a significantly reduced risk of a CID over 24 weeks versus UMEC and SAL [47].

In maintenance-naïve patients, a pooled analysis of three trials found that UMEC/VI significantly reduced the risk of CID versus TIO (figure 3) [45]. Similarly, in a prospective analysis of maintenance-naïve patients in EMAX, which analysed three definitions of CID, UMEC/VI significantly reduced the risk of a first CID versus SAL for two of the definitions (unpblished data). Additionally, a post hoc analysis of PINNACLE demonstrated GLY/FOR significantly increased the time to a first CID event over 24 weeks versus GLY and FOR monotherapy in maintenance-naïve patients [59]. While these results in maintenance-naïve patients support a benefit for dual bronchodilator treatment over monotherapy for CID, further prospective studies of the CID end-point in maintenance-naïve patients are required to evaluate whether earlier initiation of dual bronchodilation can reduce the risk of future disease deterioration.

Safety

Meta-analyses of several clinical trials have reported no increased risk of adverse events or mortality with LAMA/LABA versus monotherapy, including cardiovascular-related events [67, 68]. However, these cardiovascular data must be interpreted with caution as many COPD clinical trials exclude patients with major cardiovascular comorbidities [88]. A real-world, observational study using primary care medical records identified no significant increase in the risk of most cardiovascular-related events after 1 year of adding a second bronchodilator, although the risk of heart failure was marginally higher [89]. Large,

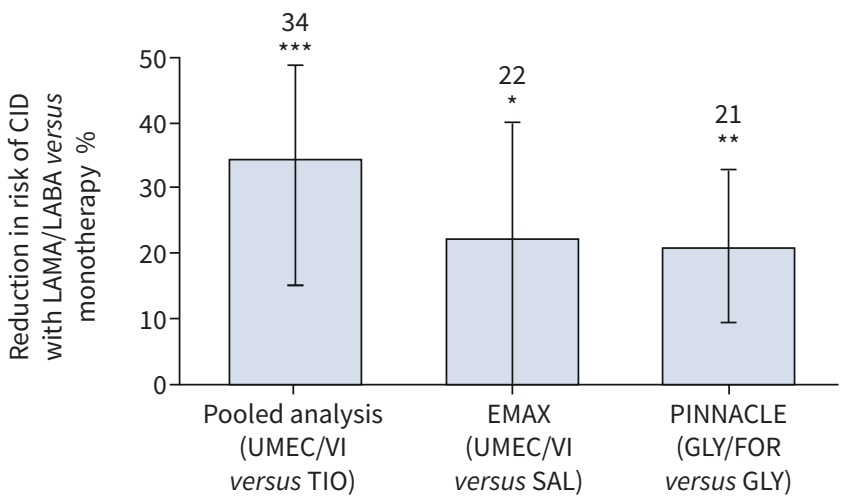

FIGURE 3 Risk of a first clinically important deterioration (CID) event over 24 weeks with dual- versus mono-bronchodilator therapy $[45,59]$. CID was defined as $\geqslant 100 \mathrm{~mL}$ decrease in forced expiratory volume in $1 \mathrm{~s}$, ?4-unit increase in St George's Respiratory Questionnaire score from baseline, and/or a moderate/severe exacerbation. LAMA: long-acting muscarinic antagonist; LABA: long-acting $\beta_{2}$-agonist; UMEC: umeclidinium; VI: vilanterol; TIO: tiotropium; SAL: salmeterol; GLY: glycopyrronium; FOR: formoterol fumarate. *: $p<0.05$; ${ }^{\star \star}: p<0.01 ;{ }^{\star \star \star}: p<0.001$ 
long-term clinical trials in patients with COPD who also have cardiovascular comorbidities are required to more thoroughly investigate any potential cardiovascular risks associated with dual bronchodilation.

Key evidence gaps around the optimal approach to initial bronchodilator therapy in COPD

Evidence to date is broadly consistent that LAMA/LABA bronchodilation provides greater efficacy than LAMA or LAMA monotherapy across lung function, symptoms and disease progression end-points, with no increased risk of AEs. Crucially, as treatment differences with dual- versus mono-bronchodilators have also been reported in maintenance-naïve patients, there are likely to be wide-ranging benefits from initiating dual therapy earlier in the disease course. Some guidelines support the use of LAMA/LABA as initial maintenance therapy for patients with symptomatic COPD, although it is not universally accepted that this approach should be used for all patients [2, 7, 90]. Evidence gaps that may improve future decision making with regard to initial maintenance therapy are discussed below.

\section{Potential confounding by ICS}

Clinical trials comparing the efficacy of dual- and mono-bronchodilation have not always accounted for concurrent ICS use, which may have confounded treatment differences. EMAX is the largest prospective study to date to investigate dual- versus mono-bronchodilation in symptomatic patients with low exacerbation risk not receiving ICS. It demonstrated early and sustained benefits in lung function and several PROs with UMEC/VI versus UMEC and SAL [47]. In contrast, two studies which allowed ICS use reported that UMEC/VI was not superior to UMEC or VI for improving TDI scores [54, 75]. Additionally, in EMAX, UMEC/VI reduced the risk of a first moderate/severe exacerbation versus SAL by $36 \%$ and 19\% versus UMEC (not significant) [47], suggesting that dual bronchodilation may reduce exacerbation risk versus LABA monotherapy when ICS use is absent; findings which contrast with those from clinical trials that permitted concurrent ICS use $[18,68]$. A recent post hoc analysis of two large RCTs also found that patients not receiving ICS had greater reductions in exacerbation risk with UMEC/VI versus placebo than with monotherapy versus placebo [60]. These findings indicate that concurrent ICS use may confound symptom and exacerbation outcome treatment differences; therefore, future studies of LAMA/LABA combination treatments should not be performed in patients with COPD who continue taking ICS.

\section{Rescue medication use}

Several clinical trials have indicated that rescue medication use affects treatment differences. A post hoc analysis of two large RCTs found that patients with low rescue medication use ( $<3.6$ puffs per day) had greater reductions in exacerbation risk versus placebo with UMEC/VI than with monotherapy, and that the incremental symptom and exacerbation benefits that occurred when escalating from mono- to dual-bronchodilation therapy were more easily detected in low versus high baseline rescue medication users [60]. High rescue medication use was also associated with reduced symptom benefits with UMEC/VI versus monotherapy in the EMAX trial [26]. These data may support early intensification of maintenance therapy to help prevent overuse of rescue medication. Patients with high use of rescue medication may represent a sub-population who required different management strategies.

\section{Disease severity}

As many patients with COPD have substantially decreased lung function at first presentation [91, 92], it is important to consider whether disease severity could impact initial dual-bronchodilator treatment responses. There are a paucity of studies of dual versus monotherapy in patients with mild COPD (defined as FEV 1 $\geqslant 80 \%$ pred; GOLD 1), who represent almost a fifth of those beginning COPD maintenance therapy [93]. A post hoc analysis by Ferguson et al. [64] found greater improvements in lung function outcomes with TIO/OLO versus TIO in maintenance-naïve patients with less severe disease (GOLD 2) versus more severe disease (GOLD 3 and 4). In EMAX, UMEC/VI provided greater improvements in TDI focal score and E-RS total score versus monotherapy regardless of baseline CAT score, with the largest benefits observed in patients with CAT scores <20 [94]. Therefore, patients with less severe COPD may particularly benefit from early initiation with dual-bronchodilator therapy, which contrasts with current GOLD recommendations that only highly symptomatic patients should initiate maintenance treatment with LAMA/ LABA [2]. Evidence suggests that COPD progresses at a faster rate in patients with less severe disease [95, 96]; therefore, providing dual bronchodilation as initial maintenance therapy in patients with less severe COPD at first presentation may help to prevent the rapid decrease in lung function seen in these patients [95, 96]. Although there is currently no evidence to show that dual therapy is more effective than monotherapy in reducing the underlying inflammatory response that drives COPD progression, short-term studies have shown that initiating maintenance treatment with dual therapy reduces the risk of a CID greater than monotherapy [45, 59, 68]. However, long-term studies are needed to confirm the effect of bronchodilator treatment in COPD disease progression. 
Furthermore, there is increasing awareness of the need to identify individuals who develop COPD at a younger age, as these patients are often not included in COPD clinical trials. Studies in patients with mild COPD, and younger patients, could help decision makers optimise diagnosis and treatment strategies earlier in the disease course.

\section{Comparative efficacy of $L A M A / L A B A$ fixed-dose combinations}

A small number of RCTs have directly compared the efficacy of LAMA/LABA fixed-dose combinations and suggest an efficacy gradient exists within this treatment class [97-99]. Superiority was observed with UMEC/VI versus TIO/OLO for improvements in trough $\mathrm{FEV}_{1}$ and reductions in rescue medication use after 8 weeks [98], and non-inferiority of IND/GLY twice daily versus UMEC/VI could not be ruled out in another study [97]. GLY/FOR was found to be non-inferior to UMEC/VI for peak $\mathrm{FEV}_{1}$, but not trough $\mathrm{FEV}_{1}$, over 24 weeks of treatment [99]. Several network meta-analyses have also identified significant differences between LAMA/LABA fixed-dose combinations for $\mathrm{FEV}_{1}$, TDI and SGRQ score efficacy, and the risk of cardiovascular adverse events [100,101]; however, others have been unable to replicate this $[102,103]$. The potential for non-equivalence of LAMA/LABA fixed-dose combinations needs to be investigated further, as this may be relevant to decision makers when evaluating the merits of dual- versus mono-bronchodilation.

\section{Discussion}

A personalised approach to initial COPD treatment has been advocated in recent years to account for differences in symptom burden and exacerbation risk between patients, with most patients recommended to initiate therapy with a single bronchodilator $[2,6]$. However, the persistent symptoms experienced by many patients when receiving mono-bronchodilation [9] and the widespread overuse of ICS-containing medications among non-exacerbating patients [104] suggests inadequate or inappropriate treatment. There are some limitations to current COPD treatment guidelines. For examples, GOLD initial treatment recommendations were mainly informed by clinical trials conducted in patients receiving maintenance treatment [2]. Furthermore, current COPD treatment recommendations place less emphasis upon early pharmacological intervention in at-risk populations than other progressive diseases, such as cardiovascular disease [105].

A potential alternative to the personalised approach to initial therapy is to initiate all symptomatic patients with dual LAMA/LABA bronchodilation. Clinical trial evidence has consistently demonstrated greater efficacy in lung function, symptom and exacerbation outcomes with LAMA/LABA therapy versus monotherapy, with a similar safety profile [42, 45, 47, 53-65]. Crucially, several recent studies have suggested that these treatment differences are also apparent in maintenance-naïve and ICS-free COPD populations, who more closely resemble those at first presentation in clinical settings [45, 58-65]. There is also evidence that LAMA/LABA combination treatments prevent future disease deteriorations, measured by CID events [41, 42, 45, 47, 59]. Considering that CID has been associated with worse prognosis in terms of mortality [46], there is a case to support the use of LAMA/LABA combinations as initial maintenance treatment to reduce future risk in addition to the current use, which is often targeted at symptom control only.

Treatment goals for COPD are broadly defined and the appropriate time frames for monitoring disease stability (or progression) are unclear. Furthermore, measuring disease activity remains a challenge that needs to be solved. Consequently, there are no accepted frameworks for monitoring and assessing whether a patient's treatment is appropriate. A variety of measures and PROs have been developed to assess disease impacts in patients with COPD, and composite end-points, such as the CID, can provide insights into disease stability and progression across multiple dimensions. Novel composite end-points appropriate for clinical settings may help physicians more easily monitor the disease course and treatment response.

There are several areas in which additional evidence is required to determine the optimal approach to the use of dual bronchodilation. It is important to identify which patient subgroups may benefit the most from early dual bronchodilation, and there remains a lack of prospective studies in maintenance-naïve patients, ICS-free patients, patients with mild COPD and young patients. There are data suggesting within-class efficacy differences between LAMA/LABAs with comparable safety, which warrant further consideration [97-99].

In conclusion, early initiation of dual-bronchodilator treatment is a potential alternative to the personalised approach currently recommended in the GOLD 2021 strategy [2]; however, further evidence is required to address the remaining evidence gaps. If future studies demonstrate that dual bronchodilation has sustained efficacy in maintenance-naïve patients across the wide range of age and disease characteristics, whilst 
reducing the risk of future disease deterioration with no increased safety risk, there could be a strong argument to initiate all newly diagnosed patients with LAMA/LABA dual bronchodilation.

Provenance: Submitted article, peer reviewed.

Acknowledgements: D. Singh is supported by the NIHR Manchester Biomedical Research Centre. The authors would like to thank Ian Naya (RAMAX Ltd, Bramhall, UK) for his contributions to the initial outline of this manuscript. Editorial support was provided by Liam Campbell and Katie White (Fishawack Indicia Ltd, UK, part of Fishawack Health), and was funded by GlaxoSmithKline.

Conflict of interest: D. Singh reports other funding from GlaxoSmithKline and non-financial support from GlaxoSmithKline, during the conduct of the study. He reports personal fees from Aerogen, AstraZeneca, Boehringer Ingelheim, Chiesi Farmaceutici S.p.A., Cipla, Genentech, GlaxoSmithKline, Glenmark, Gossamerbio, Novartis, Pfizer Inc., Pulmatrix, Teva, Theravance Biopharma, Menarini and Verona Pharma, outside the submitted work. J.F. Donohue reports other funding from GlaxoSmithKline and non-financial support from GlaxoSmithKline, during the conduct of the study. He reports personal fees from AstraZeneca, Boehringer Ingelheim, Chiesi, Circassia, GlaxoSmithKline, Mylan, Theravance and Sunovion, and other funding from AstraZeneca, Avillion, Merck, CSA and INSMED, outside the submitted work. I.H. Boucot reports other funding from GlaxoSmithKline and non-financial support from GlaxoSmithKline, during the conduct of the study. She reports personal fees from GlaxoSmithKline and other funding from GlaxoSmithKline, outside the submitted work. N.C. Barnes reports other funding from GlaxoSmithKline and non-financial support from GlaxoSmithKline, during the conduct of the study. He reports personal fees from GlaxoSmithKline and other funding from GlaxoSmithKline, outside the submitted work. C. Compton reports other funding from GlaxoSmithKline and non-financial support from GlaxoSmithKline, during the conduct of the study. He reports personal fees from GlaxoSmithKline and other funding from GlaxoSmithKline, outside the submitted work. F.J. Martinez reports other funding from GlaxoSmithKline, non-financial support from GlaxoSmithKline, and personal fees from GlaxoSmithKline, AstraZeneca, Boehringer Ingelheim and Raziel, during the conduct of the study. He reports personal fees and non-financial support from AstraZeneca, Boehringer Ingelheim, GlaxoSmithKline, Miller Communications, National Society for Continuing Education, PeerView Communications, Chiesi, Sunovion, American Thoracic Society, Rockpointe, Csl Behring, Sanofi/Regeneron, Teva, Canadian Respiratory Network, Physicians Education Resource; non-financial support from ProterrixBio, Gilead, Nitto, Zambon; personal fees, non-financial support and other from Genentech; personal fees from MD Magazine, Methodist Hospital Brooklyn, New York University, UpToDate, WebMD/MedScape, Patara/Respivant, CME Outfitters, Integritas, DevPro, Dartmouth University, IQVIA, Projects in Knowledge, Vindico, Academy for Continuing Healthcare Learning; personal fees and other from Bayer; other from Afferent/Merck, Biogen, Veracyte, Prometic, Bridge Biotherapeutics, Gala, twoXAR, AbbVie; and grants from NIH, Rare Disease Healthcare Communications, ProMedior/Roche, outside the submitted work.

Support statement: This article was funded by GlaxoSmithKline. Funding information for this article has been deposited with the Crossref Funder Registry.

\section{References}

1 Adeloye D, Chua S, Lee C, et al. Global and regional estimates of COPD prevalence: systematic review and meta-analysis. J Glob Health 2015; 5: 020415.

2 Global initiative for Chronic Obstructive Pulmonary Disease (GOLD). Global strategy for the diagnosis, management, and prevention of chronic obstructive pulmonary disease (2021 report). www.goldcopd.org/ 2021-gold-reports Date last accessed: 16 November 2020. Date last updated: November 2020.

3 Global initiative for Asthma (GINA). Global strategy for asthma management and prevention. www. ginasthma.org/gina-reports Date last accessed: 16 November 2020. Date last updated: April 2020.

4 Guimarães M, Bugalho A, Oliveira AS, et al. COPD control: can a consensus be found? Revista Portuguesa de Pneumologia (English Edition) 2016; 22: 167-176.

5 Soler-Cataluña JJ, Marzo M, Catalán P, et al. Validation of clinical control in COPD as a new tool for optimizing treatment. Int J Chron Obstruct Pulmon Dis 2018; 13: 3719-3731.

6 Sidhaye VK, Nishida K, Martinez FJ. Precision medicine in COPD: where are we and where do we need to go? Eur Respir Rev 2018; 27: 180022.

7 Nici L, Mammen MJ, Charbek E, et al. Pharmacologic management of chronic obstructive pulmonary disease. an official American Thoracic Society clinical practice guideline. Am J Respir Crit Care Med 2020; 201: e56-e69.

8 Mathioudakis AG, Vestbo J, Singh D. Long-acting bronchodilators for chronic obstructive pulmonary disease: which one(s), how, and when? Clin Chest Med 2020; 41: 463-474. 
Dransfield MT, Bailey W, Crater G, et al. Disease severity and symptoms among patients receiving monotherapy for COPD. Prim Care Respir J 2011; 20: 46-53.

Agusti A, Edwards LD, Celli B, et al. Characteristics, stability and outcomes of the 2011 GOLD COPD groups in the ECLIPSE cohort. Eur Respir J 2013; 42: 636-646.

Colak Y, Afzal S, Nordestgaard BG, et al. Prognosis of asymptomatic and symptomatic, undiagnosed COPD in the general population in Denmark: a prospective cohort study. Lancet Respir Med 2017; 5: 426-434.

Lange P, Marott JL, Vestbo J, et al. Prevalence of night-time dyspnoea in COPD and its implications for prognosis. Eur Respir J 2014; 43: 1590-1598.

Stephenson JJ, Wertz D, Gu T, et al. Clinical and economic burden of dyspnea and other COPD symptoms in a managed care setting. Int J Chron Obstruct Pulmon Dis 2017; 12: 1947-1959.

Punekar YS, Naya I, Small M, et al. Bronchodilator reliever use and its association with the economic and humanistic burden of COPD: a propensity-matched study. J Med Econ 2017; 20: 28-36.

Singh D, Roche N, Halpin D, et al. Current controversies in the pharmacological treatment of chronic obstructive pulmonary disease. Am J Respir Crit Care Med 2016; 194: 541-549.

Kerwin EM, Boucot IH, Vogelmeier CF, et al. Early and sustained symptom improvement with umeclidinium/ vilanterol versus monotherapy in COPD: a post hoc analysis of the EMAX randomised controlled trial. Ther Adv Respir Dis 2020; 14: 1753466620926949.

Jones PW, Agusti AG. Outcomes and markers in the assessment of chronic obstructive pulmonary disease. Eur Respir J 2006; 27: 822-832.

Donohue JF, Jones PW, Bartels C, et al. Correlations between $\mathrm{FEV}_{1}$ and patient-reported outcomes: a pooled analysis of 23 clinical trials in patients with chronic obstructive pulmonary disease. Pulm Pharmacol Ther 2018; 49: 11-19.

Westwood M, Bourbeau J, Jones PW, et al. Relationship between FEV $_{1}$ change and patient-reported outcomes in randomised trials of inhaled bronchodilators for stable COPD: a systematic review. Respir Res 2011; 12: 40.

Kostikas K, Greulich T, Mackay AJ, et al. Treatment response in COPD: does FEV 1 say it all? A post hoc analysis of the CRYSTAL study. ERJ Open Res 2019; 5: 00243-2018.

Kessler R, Partridge MR, Miravitlles M, et al. Symptom variability in patients with severe COPD: a pan-European cross-sectional study. Eur Respir J 2011; 37: 264-272.

Mahler DA, Weinberg DH, Wells CK, et al. The measurement of dyspnea. Contents, interobserver agreement, and physiologic correlates of two new clinical indexes. Chest 1984; 85: 751-758.

Jones PW, Harding G, Berry P, et al. Development and first validation of the COPD Assessment Test. Eur Respir J 2009; 34: 648-654.

Leidy NK, Sexton CC, Jones PW, et al. Measuring respiratory symptoms in clinical trials of COPD: reliability and validity of a daily diary. Thorax 2014; 69: 443-449.

Jones P, Quirk F, Baveystock C. The St George's respiratory questionnaire. Respir Med 1991; 85: 25-31.

Maltais F, Naya IP, Vogelmeier CF, et al. Salbutamol use in relation to maintenance bronchodilator efficacy in COPD: a prospective subgroup analysis of the EMAX trial. Respir Res 2020; 21: 280.

Cazzola M, Hanania NA, MacNee W, et al. A review of the most common patient-reported outcomes in COPD- revisiting current knowledge and estimating future challenges. Int J Chron Obstruct Pulmon Dis 2015; 10: $725-738$.

Soler-Cataluna JJ, Martinez-Garcia MA, Roman Sanchez P, et al. Severe acute exacerbations and mortality in patients with chronic obstructive pulmonary disease. Thorax 2005; 60: 925-931.

Halpin DM, Decramer M, Celli B, et al. Exacerbation frequency and course of COPD. Int J Chron Obstruct Pulmon Dis 2012; 7: 653-661.

Calverley PM, Tetzlaff K, Dusser D, et al. Determinants of exacerbation risk in patients with COPD in the TIOSPIR study. Int J Chron Obstruct Pulmon Dis 2017; 12: 3391-3405. obstructive pulmonary disease with the new Global Initiative for Chronic Obstructive Lung Disease 2017 classification: a cohort study. Lancet Respir Med 2018; 6: 204-212.

Lange P, Marott JL, Vestbo J, et al. Prediction of the clinical course of chronic obstructive pulmonary disease, using the new GOLD classification: a study of the general population. Am J Respir Crit Care Med 2012; 186: 975-981.

Nishimura K, Izumi T, Tsukino M, et al. Dyspnea is a better predictor of 5-year survival than airway obstruction in patients with COPD. Chest 2002; 121: 1434-1440.

Burgel PR, Nesme-Meyer P, Chanez P, et al. Cough and sputum production are associated with frequent exacerbations and hospitalizations in COPD subjects. Chest 2009; 135: 975-982.

Cardoso J, Coelho R, Rocha C, et al. Prediction of severe exacerbations and mortality in COPD: the role of exacerbation history and inspiratory capacity/total lung capacity ratio. Int J Chron Obstruct Pulmon Dis 2018; 13: $1105-1113$. 
Miravitlles $\mathrm{M}$, Worth $\mathrm{H}$, Soler-Cataluna JJ, et al. The relationship between 24-hour symptoms and COPD exacerbations and healthcare resource use: results from an Observational Study (ASSESS). COPD 2016; 13 561-568.

Bailey WC, Sciurba FC, Hanania NA, et al. Development and validation of the Chronic Obstructive Pulmonary Disease Assessment Questionnaire (COPD-AQ). Prim Care Respir J 2009; 18: 198-207.

José Soler-Cataluña J, Alcázar-Navarrete B, Miravitlles M. The concept of control in COPD: a new proposal for optimising therapy. Eur Respir J 2014; 44: 1072-1075.

Barrecheguren M, Kostikas $\mathrm{K}$, Mezzi $\mathrm{K}$, et al. COPD clinical control as a predictor of future exacerbations: concept validation in the SPARK study population. Thorax 2020; 75: 351-353.

Singh D, Criner GJ, Naya I, et al. Measuring disease activity in COPD: is clinically important deterioration the answer? Respir Res 2020; 21: 134.

Singh D, Maleki-Yazdi MR, Tombs L, et al. Prevention of clinically important deteriorations in COPD with umeclidinium/vilanterol. Int J Chron Obstruct Pulmon Dis 2016; 11: 1413-1424.

Anzueto AR, Vogelmeier CF, Kostikas K, et al. The effect of indacaterol/glycopyrronium versus tiotropium or salmeterol/fluticasone on the prevention of clinically important deterioration in COPD. Int J Chron Obstruct Pulmon Dis 2017; 12: 1325-1337.

Anzueto AR, Kostikas K, Mezzi K, et al. Indacaterol/glycopyrronium versus salmeterol/fluticasone in the prevention of clinically important deterioration in COPD: results from the FLAME study. Respir Res 2018; 19: 121. Singh D, Maleki-Yazdi MR, Tombs L, et al. Clinically important deteriorations in COPD as a measure of response to dual and mono bronchodilator therapy with and without inhaled corticosteroids. Eur Respir J 2015; 46: Suppl. 59, PA1487.

Maleki-Yazdi MR, Singh D, Anzueto A, et al. Assessing short-term deterioration in maintenance-naive patients with COPD receiving umeclidinium/vilanterol and tiotropium: a pooled analysis of three randomized trials. Adv Ther 2017; 33: 2188-2199.

Naya IP, Tombs L, Muellerova $\mathrm{H}$, et al. Long-term outcomes following first short-term clinically important deterioration in COPD. Respir Res 2018; 19: 222.

Maltais F, Bjermer L, Kerwin EM, et al. Efficacy of umeclidinium/vilanterol versus umeclidinium and salmeterol monotherapies in symptomatic patients with COPD not receiving inhaled corticosteroids: the EMAX randomised trial. Respir Res 2019; 20: 238.

Naya I, Compton C, Ismaila AS, et al. Preventing clinically important deterioration with single-inhaler triple therapy in COPD. ERJ Open Res 2018; 4: 00047-2018.

Rabe KF, Halpin D, Martinez F, et al. A103 COPD: Disease progression and prognosis. Am J Respir Crit Care Med 2017; 195: A2717.

Han MK, Criner GJ, Dransfield MT, et al. A102 COPD: therapy. Am J Respir Crit Care Med 2019; 199: A2438.

Rabe KF, Halpin DMG, Han MK, et al. Composite endpoints in COPD: clinically important deterioration in the UPLIFT trial. Respir Res 2020; 21: 177.

Han MK, Criner GJ, Dransfield MT, et al. Prognostic value of clinically important deterioration in COPD: IMPACT trial analysis. ERJ Open Res 2021; 7: 00663-2020.

Wedzicha JA, Decramer M, Ficker JH, et al. Analysis of chronic obstructive pulmonary disease exacerbations with the dual bronchodilator QVA149 compared with glycopyrronium and tiotropium (SPARK): a randomised, double-blind, parallel-group study. Lancet Respir Med 2013; 1: 199-209.

Donohue JF, Maleki-Yazdi MR, Kilbride S, et al. Efficacy and safety of once-daily umeclidinium/vilanterol 62.5/25 mcg in COPD. Respir Med 2013; 107: 1538-1546.

Donohue JF, Soong W, Wu X, et al. Long-term safety of aclidinium bromide/formoterol fumarate fixed-dose combination: results of a randomized 1-year trial in patients with COPD. Respir Med 2016; 116: 41-48.

Bateman ED, Chapman KR, Singh D, et al. Aclidinium bromide and formoterol fumarate as a fixed-dose combination in COPD: pooled analysis of symptoms and exacerbations from two six-month, multicentre, randomised studies (ACLIFORM and AUGMENT). Respir Res 2015; 16: 92.

7 Ferguson GT, Karpel J, Bennett N, et al. Effect of tiotropium and olodaterol on symptoms and patient-reported outcomes in patients with COPD: results from four randomised, double-blind studies. NPJ Prim Care Respir Med 2017; $27: 7$.

5 Singh D, Gaga M, Schmidt O, et al. Effects of tiotropium+olodaterol versus tiotropium or placebo by COPD disease severity and previous treatment history in the OTEMTO(R) studies. Respir Res 2016; 17: 73.

Zheng J, Xu J-F, Jenkins M, et al. Glycopyrrolate/formoterol fumarate metered dose inhaler for maintenance-naïve patients with chronic obstructive pulmonary disease: a post-hoc analysis of the randomized PINNACLE trials. Respir Res 2020; 21: 69.

60 Naya I, Tombs L, Lipson DA, et al. Impact of prior and concurrent medication on exacerbation risk with long-acting bronchodilators in chronic obstructive pulmonary disease: a post hoc analysis. Respir Res 2019; 20: 60.

1 Muro S, Yoshisue $\mathrm{H}$, Kostikas $\mathrm{K}$, et al. Indacaterol/glycopyrronium versus tiotropium or glycopyrronium in long-acting bronchodilator-naive COPD patients: a pooled analysis. Respirology 2020; 25: 393-400. 
62

Bjermer LH, Kerwin E, Maltais F, et al. B45 COPD: Treatment. Am J Respir Crit Care Med 2019; 199: A3317. Singh D, D'Urzo AD, Donohue JF, et al. An evaluation of single and dual long-acting bronchodilator therapy as effective interventions in maintenance therapy-naïve patients with COPD. Int J Chron Obstruct Pulmon Dis 2019; 14: 2835-2848.

Ferguson GT, Fležar M, Korn S, et al. Efficacy of tiotropium+olodaterol in patients with chronic obstructive pulmonary disease by initial disease severity and treatment intensity: a post hoc analysis. Adv Ther 2015; 32: 523-536.

Takahashi K, Uchida M, Kato G, et al. First-line treatment with tiotropium/olodaterol improves physical activity in patients with treatment-naïve chronic obstructive pulmonary disease. Int $\mathrm{J}$ Chron Obstruct Pulmon Dis 2020; 15: 2115-2126.

Buhl R, de la Hoz A, Xue W, et al. Efficacy of tiotropium/olodaterol compared with tiotropium as a first-line maintenance treatment in patients with COPD who are naive to LAMA, LABA and ICS: pooled analysis of four clinical trials. Adv Ther 2020; 37: 4175-4189.

Rodrigo GJ, Price D, Anzueto A, et al. LABA/LAMA combinations versus LAMA monotherapy or LABA/ICS in COPD: a systematic review and meta-analysis. Int J Chron Obstruct Pulmon Dis 2017; 12: 907-922.

Oba Y, Sarva ST, Dias S. Efficacy and safety of long-acting beta-agonist/long-acting muscarinic antagonist combinations in COPD: a network meta-analysis. Thorax 2016; 71: 15-25.

Oba Y, Keeney E, Ghatehorde N, et al. Dual combination therapy versus long-acting bronchodilators alone for chronic obstructive pulmonary disease (COPD): a systematic review and network meta-analysis. Cochrane Database Syst Rev 2018; 12: CD012620.

Calzetta L, Rogliani P, Matera MG, et al. A systematic review with meta-analysis of dual bronchodilation with LAMA/LABA for the treatment of stable COPD. Chest 2016; 149: 1181-1196.

D'Urzo AD, Rennard SI, Kerwin EM, et al. Efficacy and safety of fixed-dose combinations of aclidinium bromide/formoterol fumarate: the 24-week, randomized, placebo-controlled AUGMENT COPD study. Respir Res 2014; 15: 123.

Buhl R, Maltais F, Abrahams R, et al. Tiotropium and olodaterol fixed-dose combination versus mono-components in COPD (GOLD 2-4). Eur Respir J 2015; 45: 969-979.

Maleki-Yazdi MR, Kaelin T, Richard N, et al. Efficacy and safety of umeclidinium/vilanterol 62.5/25 mcg and tiotropium $18 \mathrm{mcg}$ in chronic obstructive pulmonary disease: results of a 24-week, randomized, controlled trial. Respir Med 2014; 108: 1752-1760.

Calzetta L, Ora J, Cavalli F, et al. Impact of LABA/LAMA combination on exercise endurance and lung hyperinflation in COPD: a pair-wise and network meta-analysis. Respir Med 2017; 129: 189-198.

Decramer M, Anzueto A, Kerwin E, et al. Efficacy and safety of umeclidinium plus vilanterol versus tiotropium, vilanterol, or umeclidinium monotherapies over 24 weeks in patients with chronic obstructive pulmonary disease: results from two multicentre, blinded, randomised controlled trials. Lancet Respir Med 2014; 2: 472-486.

Mahler DA, Kerwin E, Ayers T, et al. FLIGHT1 and FLIGHT2: efficacy and safety of QVA149 (Indacaterol/ Glycopyrrolate) versus its monocomponents and placebo in patients with chronic obstructive pulmonary disease. Am J Respir Crit Care Med 2015; 192: 1068-1079.

Maltais F, Aumann JL, Kirsten AM, et al. Dual bronchodilation with tiotropium/olodaterol further reduces activity-related breathlessness versus tiotropium alone in COPD. Eur Respir J 2019; 53: 1802049.

Singh S, Maltais F, Tombs L, et al. Relationship between exercise endurance and static hyperinflation in a post hoc analysis of two clinical trials in patients with COPD. Int J Chron Obstruct Pulmon Dis 2018; 13: 203-215.

Ichinose M, Minakata Y, Motegi T, et al. Efficacy of tiotropium/olodaterol on lung volume, exercise capacity, and physical activity. Int J Chron Obstruct Pulmon Dis 2018; 13: 1407-1419.

Minakata Y, Motegi T, Ueki J, et al. Effect of tiotropium/olodaterol on sedentary and active time in patients with COPD: post hoc analysis of the VESUTO((R)) study. Int J Chron Obstruct Pulmon Dis 2019; 14: 1789-1801. Singh D, Jones PW, Bateman ED, et al. Efficacy and safety of aclidinium bromide/formoterol fumarate fixed-dose combinations compared with individual components and placebo in patients with COPD (ACLIFORM-COPD): a multicentre, randomised study. BMC Pulm Med 2014; 14: 178.

82 Hanania NA, Tashkin DP, Kerwin EM, et al. Long-term safety and efficacy of glycopyrrolate/formoterol metered dose inhaler using novel co-suspension delivery technology in patients with chronic obstructive pulmonary disease. Respir Med 2017; 126: 105-115.

Beeh KM, Korn S, Beier J, et al. Effect of QVA149 on lung volumes and exercise tolerance in COPD patients: the BRIGHT study. Respir Med 2014; 108: 584-592.

O'Donnell DE, Casaburi R, Frith $\mathrm{P}$, et al. Effects of combined tiotropium/olodaterol on inspiratory capacity and exercise endurance in COPD. Eur Respir J 2017; 49: 1601348.

Calverley PMA, Anzueto AR, Carter K, et al. Tiotropium and olodaterol in the prevention of chronic obstructive pulmonary disease exacerbations (DYNAGITO): a double-blind, randomised, parallel-group, active-controlled trial. Lancet Respir Med 2018; 6: 337-344. 
Eriksson G, Calverley PM, Jenkins CR, et al. The effect of COPD severity and study duration on exacerbation outcome in randomized controlled trials. Int J Chron Obstruct Pulmon Dis 2017; 12: 1457-1468.

Kerwin EM, Maltais F, Boucot I, et al. Analysis of a composite endpoint of exacerbation and early study treatment withdrawal in symptomatic patients with COPD free of inhaled corticosteroids: a post hoc analysis of the EMAX trial. Am J Respir Crit Care Med 2020; 201: A457.

Lahousse L, Verhamme KM, Stricker BH, et al. Cardiac effects of current treatments of chronic obstructive pulmonary disease. Lancet Respir Med 2016; 4: 149-164.

Suissa S, Dell'Aniello S, Ernst P. Concurrent use of long-acting bronchodilators in COPD and the risk of adverse cardiovascular events. Eur Respir J 2017; 49: 1602245.

National Institute for Health and Care Excellence. Chronic obstructive pulmonary disease in over 16s: diagnosis and management. www.nice.org.uk/guidance/NG115 Date last accessed: 16 November 2020. Date last updated: July 2019.

Raluy-Callado M, Lambrelli D, MacLachlan S, et al. Epidemiology, severity, and treatment of chronic obstructive pulmonary disease in the United Kingdom by GOLD 2013. Int J Chron Obstruct Pulmon Dis 2015; 10: 925-937.

Sutherland ER, Cherniack RM. Management of chronic obstructive pulmonary disease. N Engl J Med 2004; 350: 2689-2697.

Halpin DMG, de Jong HJI, Carter V, et al. Distribution, temporal stability and appropriateness of therapy of patients with COPD in the UK in relation to GOLD 2019. EClinicalMedicine 2019; 14: 32-41.

Vogelmeier CF, Kerwin EM, Bjermer LH, et al. Impact of baseline COPD symptom severity on the benefit from dual versus mono-bronchodilators: an analysis of the EMAX randomised controlled trial. Ther Adv Respir Dis 2020; 14: 1753466620968500.

Vestbo J, Edwards LD, Scanlon PD, et al. Changes in forced expiratory volume in 1 second over time in COPD. N Engl J Med 2011; 365: 1184-1192.

Bridevaux PO, Gerbase MW, Probst-Hensch NM, et al. Long-term decline in lung function, utilisation of care and quality of life in modified GOLD stage 1 COPD. Thorax 2008; 63: 768-774.

Kerwin E, Ferguson GT, Sanjar S, et al. Dual bronchodilation with indacaterol maleate/glycopyrronium bromide compared with umeclidinium bromide/vilanterol in patients with moderate-to-severe COPD: results from two randomized, controlled, cross-over studies. Lung 2017; 195: 739-747.

Feldman GJ, Sousa AR, Lipson DA, et al. Comparative efficacy of once-daily umeclidinium/vilanterol and tiotropium/olodaterol therapy in symptomatic chronic obstructive pulmonary disease: a randomized study. Adv Ther 2017; 34: 2518-2533.

Maltais F, Ferguson GT, Feldman GJ, et al. A randomized, double-blind, double-dummy study of glycopyrrolate/formoterol fumarate metered dose inhaler relative to umeclidinium/vilanterol dry powder inhaler in COPD. Adv Ther 2019; 36: 2434-2449.

Sion KYJ, Huisman EL, Punekar YS, et al. A network meta-analysis of long-acting muscarinic antagonist (LAMA) and long-acting $\beta 2$-agonist (LABA) combinations in COPD. Pulm Ther 2017; 3: 297-316.

1 Rogliani P, Matera MG, Ritondo BL, et al. Efficacy and cardiovascular safety profile of dual bronchodilation therapy in chronic obstructive pulmonary disease: a bidimensional comparative analysis across fixed-dose combinations. Pulm Pharmacol Ther 2019; 59: 101841.

Aziz MIA, Tan LE, Wu DB, et al. Comparative efficacy of inhaled medications (ICS/LABA, LAMA, LAMA/LABA and SAMA) for COPD: a systematic review and network meta-analysis. Int J Chron Obstruct Pulmon Dis 2018; 13: 3203-3231.

03 Siddiqui MK, Shukla P, Jenkins M, et al. Systematic review and network meta-analysis of the efficacy and safety of glycopyrrolate/formoterol fumarate metered dose inhaler in comparison with other long-acting muscarinic antagonist/long-acting beta2-agonist fixed-dose combinations in COPD. Ther Adv Respir Dis 2019; 13: 1753466619894502.

104 Griffith MF, Feemster LC, Zeliadt SB, et al. Overuse and misuse of inhaled corticosteroids among veterans with COPD: a cross-sectional study evaluating targets for de-implementation. J Gen Intern Med 2020; 35: 679-686.

National Institute for Health and Care Excellence. Cardiovascular disease risk assessment and prevention. https://bnf.nice.org.uk/treatment-summary/cardiovascular-disease-risk-assessment-and-prevention.html Date last accessed: 2 January 2020. Date last updated: January 2020. 